\title{
Stress, anxiety, depression, and resilience in Canadian farmers
}

\author{
Andria Jones-Bitton ${ }^{1}\left[\right.$ ] $\cdot$ Colleen Best ${ }^{1} \cdot$ Jennifer MacTavish ${ }^{2} \cdot$ Stephen Fleming ${ }^{3} \cdot$ Sandra Hoy $^{4}$
}

Received: 4 February 2019 / Accepted: 3 June 2019 / Published online: 13 June 2019

(c) The Author(s) 2019

\begin{abstract}
Purpose To estimate the prevalence of stress, anxiety, depression, and resilience amongst Canadian farmers.

Methods An online cross-sectional survey using validated psychometric scales [Perceived Stress Scale (PSS), Hospital Anxiety and Depression Scale, Connor-Davidson Resilience Scale] conducted with farmers in Canada between September 2015 and February 2016.

Results 1132 farmers participated in the study. The average PSS score was 18.9 . Approximately $57 \%$ and $33 \%$ of participants were classified as possible and probable cases for anxiety, respectively; the respective proportions for depression were $34 \%$ and $15 \%$. The average resilience score was 71.1. Scores for stress, anxiety, and depression were higher, and resilience lower, than reported normative data. Females scored less favorably on all mental health outcomes studied, highlighting important gender disparities.

Conclusions These results highlight a significant public health concern amongst farmers, and illustrate a critical need for research and interventions related to farmer mental health. These findings are important for policymakers, physicians, and public and mental health service providers, and can help to inform decision-making, policy recommendations, resource allocation, and development and delivery of training programs for farmers.
\end{abstract}

Keywords Stress · Anxiety $\cdot$ Depression $\cdot$ Resilience $\cdot$ Farmers · Canada

\section{Introduction}

The occupational hazards associated with farming are well recognized and can have impacts not only on physical health [1], but also mental health. For example, farmers in the United Kingdom (UK), United States (US), Australia, Finland, and Norway are reported to experience high levels or risk of stress [2-5], anxiety [6], depression [6-8], psychological distress [9], and psychological morbidity [10]. Regrettably, estimates of mental health outcomes in

Andria Jones-Bitton

aqjones@uoguelph.ca

1 Department of Population Medicine, Ontario Veterinary College, University of Guelph, 50 Stone Road East, Guelph, ON N1G 2W1, Canada

2 Ontario Sheep Farmers, 130 Malcolm Road, Guelph, ON N1K 1B1, Canada

3 Department of Psychology, York University, Faculty of Health, 4700 Keele Street, Toronto, ON M3J 1P3, Canada

4 School of Social Work, Laurentian University, 935 Ramsey Lake Road, Sudbury, ON P3E 2C6, Canada
Canadian farmers are lacking. Given the important role farmers play in Canadian economy and international trade [11], and the global need for increased and sustainable agriculture to meet the challenge of feeding 9 billion people by 2050 [12], this represents a serious gap in knowledge.

Resilience is the ability to "thrive in the face of adversity" and is a learned process that can help to protect against occupational stresses and mental illness [13; p. 76]. However, very little research has been conducted on resilience in farmers, representing another important area for investigation.

Addressing the gaps in understanding of mental health and resilience amongst farmers is key to supporting agriculture and food systems, informing resource and training development, and allocating resources and service delivery. Hence, the objectives of this study were to estimate the prevalence of stress, anxiety, depression, and resilience amongst Canadian farmers. 


\section{Methods}

\section{Study design}

A cross-sectional study was conducted from September 12, 2015 to February 9, 2016, using an online questionnaire administered via Qualtrics (Provo, UT, USA). We contacted provincial and national agricultural organizations across Canada by email and/or telephone to ask them to share news of the study and distribute the survey web link to their members via emails, listserves, newsletters, magazines, and social media (predominantly Twitter). Inclusion criteria were: being 18 years of age or older, able to read and write in English, and being a self-identified farmer from any Canadian agricultural commodity group. Informed written consent was obtained prior to starting the questionnaire, and the data were collected anonymously. Participants were given the opportunity to submit their email address (separate from their questionnaire responses) to be entered into a draw to win one of three $\$ 250$ cash prizes. The Research Ethics Board at the University of Guelph approved the study (15-JN-007).

\section{Questionnaire}

The questionnaire contained the following three validated, self-report, mental health scales:

- Perceived Stress Scale (PSS): this commonly used, 10-item scale, with established reliability and validity [14], measures "a global level of perceived stress", "the degree to which situations in one's life are appraised as stressful" and how "unpredictable, uncontrollable, and overloading" respondents found their lives to be in the previous month [15; p. 387]. Items are measured on a 5 -point Likert scale (0-4). Responses were analyzed as per the scale instructions; all items were summed to produce an overall score (range $0-40$ ), where greater scores signify higher levels of perceived stress.

- Hospital Anxiety and Depression Scale (HADS): this is a 14-item measure with two distinct subscales: anxiety ("restless, anxious moods, and thoughts") and depression ("state of loss of interest and diminished pleasure response") [16; p. 2] in the past week. Both subscales contain seven items; responses are scored on a 4-point Likert scale (0-3) yielding a score range of $0-21$ [16]. As per scale instructions, the anxiety and depression subscales were scored separately by summing the items and then classifying "caseness" as: Normal (0-7), Mild (8-10), Moderate (11-15), and Severe $(\geq 16)$ [16]. Other authors have also defined "possi- ble" (cut-point score of $\geq 8$ ) and "probable" (cut-point score $\geq 11)$ case categories for anxiety and depression [17]. The HADS has been extensively validated [18] and has been used in studies of farmers in England [2], France [19], and Norway [6, 8]. Nevertheless, there has been some question as to whether the HADS is able to consistently differentiate between anxiety and depression constructs (e.g. [20]), leading to investigation of the HADS-total score (i.e., the sum of the scores from HADS-A and HADS-D) as a measure of overall psychological distress [20, 21]. A review of the HADS included 16 different articles with cut-point scores for HADS-total ranging from $\geq 8$ to $\geq 21$ [18]. Pallan and Tennant reported the HADS-total with cut-point score of $\geq 12$ to be a viable means of classifying psychological distress [21]; hence, we also used this approach here.

- Connor-Davidson Resilience Scale (CD-RISC): this 25-item scale is used to measure resilience as "successful stress-coping ability" [13; p. 77]. It is reported to have sound psychometric properties and good internal consistency and test-retest reliability [13, 22]. As per scale instructions, responses to 5-point Likert scale (0-4) were summed to produce an overall resilience score (range $0-100$ ), with higher scores indicative of higher levels of resilience.

Questions were also included to collect participant demographic data, including age, self-identified gender, and farming commodity. Two questions ("Are you currently on medication for mental illness (e.g., depression, anxiety, schizophrenia, bipolar disorder)?" and "Have you ever suffered from a mental illness in the past?") were used to provide insight into self-reported history of mental illness. The full questionnaire was designed to take approximately 15-20 min to complete.

\section{Sample size}

As there were no published prevalence estimates of the mental health outcomes of interest amongst Canadian farmers for use in sample size calculations, an a priori estimate of 50\% was used conservatively to maximize the required sample size. A minimum required sample size of 385 farmers was calculated using an allowable error of 5\% and confidence level of $95 \%$ [23].

\section{Statistical analyses}

Descriptive statistics [means, medians (M), interquartile ranges (IQR), and percentages] were used to examine the data. Person mean imputation was used to account for missing data if only one value was missing per scale (PSS, 
CD-RISC) or subscale (HADS), as has been reported elsewhere $[17,24]$. If an observation had two or more missing values per observation per mental health scale or subscale, it was deemed invalid and dropped from that analysis. To provide some insight for the potential for non-response bias, we applied the extrapolation method of comparing earlyto-late responders, as described by Lindner et al. [25]. In this analysis, late responders (defined here as participants responding in the last third of the study period) are used as a proxy measure of non-responders, and statistical comparisons are made between early and late responders on primary variables of interest as a means of addressing non-response error [25]. Chi square tests were used to assess whether differences in mental health outcomes existed between early and late responders. All statistical analyses were conducted using Stata v.15 (StataCorp, College Station, TX, USA).

\section{Results}

\section{Study population}

A total of 1132 participants returned a questionnaire. As no questions were mandatory, response percentages and sample sizes per question vary, as noted. The average participant age $(n=980)$ was 46.6 years (SD 13.3; IQR 28-64; range 19-88), which is lower than the average age reported for farm operators in Canada (55.0 years) [26]. Of participants responding to the open-ended question on gender $(n=977)$ : $69.4 \%$ identified as male, $30.4 \%$ identified as female, and $0.2 \%$ identified as gender-queer. For reasons of maintaining anonymity and given small group sample size in the genderqueer category, data for these participants were not reported separately, and were instead reported with the missing gender category. The male and female breakdown observed here is close to the sex breakdown reported for farm operators in 2016 in Canada (71.3\% male and $28.7 \%$ female) [27]. In identifying their relationship status $(n=986)$, most participants were married $(77.8 \%)$ or in a committed relationship (9.9\%); the remainder were single $(9.0 \%)$, separated/ divorced $(2.0 \%)$, widowed $(0.7 \%)$, or identified their relationship status as "other" (0.5\%). One-quarter (242/970) of participants self-reported having a previous mental illness; 9.1\% (88/969) reported currently taking medications for mental illness.

All provinces in Canada were represented (Table 1), although Ontario participants were the majority (72.5\%). The percentage of participants by province is compared to 2016 national census data of the number of farm operators per province [28] in Table 1. Participants $(n=1132)$ were asked to select from a list all of the commodity groups to which they belonged. The represented commodities are presented in Table 1 and compared to 2016 national census data for farm type [29]. A total of 708 (62.5\%) participants identified as crop growers; of these, 529 (46.7\% of all participants) grew crops and were involved in at least one other commodity, and 179 (15.8\% of all participants) only grew crops. Approximately half of all participants were involved in more than one commodity $(53 \% ; 600 / 1132)$.

\section{Perceived stress}

The average PSS score was $18.9(n=1127$, SD $4.9, M=19$, IQR 15-22). Of these, 972 participants self-identified their gender: amongst men $(n=677)$, the average score was 18.3 (SD 4.9, $M=18$, IQR 15-22); amongst women $(n=295)$, it was 20.1 (SD 4.9, $M=20$, IQR 16-24). For the 153 participants who did not report gender or identified as genderqueer, the average score was 18.7 (SD $4.8 ; M=19$, IQR 15-22).

\section{Anxiety and depression}

The results from the HADS are presented in Table 2. Approximately $57 \%$ and $33 \%$ of all participants were classified as possible and probable cases for anxiety, respectively. Approximately $34 \%$ and $15 \%$ of all participants were classified as possible and probable cases of depression, respectively. Nearly two-thirds of participants (61.9\%) had HADStotal scores $\geq 12$, indicating psychological distress. Anxiety, depression, and HADS-total scores, and the percentage of probable cases of anxiety, depression, and psychological distress, were higher in females than in the overall sample and males.

\section{Resilience}

Amongst the 968 participants who provided responses for the CD-RISC, the average resilience score was 71.1 (SD 15.6; $M=72$; IQR 61-90). Amongst males $(n=659)$, the average score was 71.8 (SD 15.5; $M=73$; IQR 62-83), and amongst females $(n=292)$, it was 69.5 (SD 15.7; $M=70$; IQR 59-81). Amongst the participants who responded to the CD-RISC and did not specify gender $(n=15)$ or identified as gender-queer $(n=2)$, the average resilience score was 70.1 (SD 12.3; $M=71$; IQR 66-78).

\section{Discussion}

To the authors' knowledge, this is the first published study to quantify resilience in farmers and the first to investigate farmer mental health in Canada using validated psychometric tools. These results shed light on mental health issues affecting the agricultural community in Canada, which is particularly concerning given the importance of agriculture 
Table 1 Breakdown of farm type and province in the study sample compared to 2016 Canadian census data (Statistics Canada, 2016 Census of Agriculture-Table 32-10-0403-01 Farms classified by farm type and Table 32-10-0440-01 total number of farms and farm operators)

\begin{tabular}{|c|c|c|}
\hline Characteristic & Study sample \# (\%) & 2016 census \# $(\%)$ \\
\hline Farm type & $n=1132$ & $n=193,492$ \\
\hline Dairy cattle & $410(36.2)$ & $10,525(5.4)$ \\
\hline Beef cattle & $248(21.9)$ & $36,013(18.6)$ \\
\hline Pigs & $126(11.1)$ & $3305(1.7)$ \\
\hline Broiler chicken & $114(10.1)$ & $2175(1.1)$ \\
\hline Layer chicken & $91(8.0)$ & $2008(1.0)$ \\
\hline Turkeys & $36(3.2)$ & $294(0.15)$ \\
\hline Sheep (meat and dairy combined) & $114(10.1)$ & $2189(1.1)$ \\
\hline Goat (meat and dairy combined) & $36(3.2)$ & $867(0.44)$ \\
\hline Other animal & $44^{\mathrm{a}}(3.9)$ & $18,143^{\mathrm{b}}(9.4)$ \\
\hline Crops & $708(62.5)$ & $90,011(46.5)$ \\
\hline Horticulture & $51(4.5)$ & $20,547(10.6)$ \\
\hline Other farming ${ }^{\mathrm{c}}$ & $20(1.8)$ & $7415(3.8)$ \\
\hline Number of farmers by province & $n=1132$ & $n=271,935$ \\
\hline Ontario & $821(72.5)$ & $70,470(25.9)$ \\
\hline Alberta & $98(8.7)$ & $41,995(15.4)$ \\
\hline British Columbia & $60(5.3)$ & $4630(1.7)$ \\
\hline Manitoba & $53(4.7)$ & $3005(1.1)$ \\
\hline Saskatchewan & $51(4.5)$ & $500(0.2)$ \\
\hline New Brunswick & $18(1.6)$ & $20,140(7.4)$ \\
\hline Nova Scotia & $13(1.2)$ & $45,350(16.7)$ \\
\hline Quebec & $10(0.9)$ & $57,605(21.1)$ \\
\hline Newfoundland and Labrador & $5(0.4)$ & $26,430(9.7)$ \\
\hline Prince Edward Island & $3(0.3)$ & $1810(0.7)$ \\
\hline
\end{tabular}

${ }^{\mathrm{a}}$ Other poultry, rabbits, veal, bison, equine, fish, game birds

${ }^{\mathrm{b}}$ Other poultry, equine, fur-bearing, animal combination, other miscellaneous animal production

${ }^{\mathrm{c}}$ Apiculture, maple syrup

to Canadian economy, trade, and employment [11]. Comparisons of the present results with studies that used the same psychometric scales follows below; however, comparisons may be hindered by different study periods. Where specific Canadian data were unavailable, we drew on the international literature for interpretation of results. On-going qualitative work in the lead author's research laboratory explores Canadian farmers' perceptions of stressors that lead to negative impacts on mental health, and the resulting impacts this has on their farm production and home lives.

The mean PSS scores reported here for males (18.3) and females (20.1) are notably higher than reported normative data means from the US general population (12.1 and 13.7 for males and females, respectively) [30]. The PSS scores for males here are also higher than those reported for male grain farmers in Ohio, US (calculated average 10.9) [7] and rural men (not necessarily farmers) in Australia (15.0) [31]. Reasons for high stress amongst farmers have been reported to include: unpredictable weather; animal disease; economic stresses; overwork; burden of paperwork/bureaucracy; media criticism; and social isolation [2, 32]. High stress amongst farmers is associated with increased risk of farm injury [1, 33] and depression [7], while stress in general is associated with mental (e.g., depression and anxiety) and physical (e.g., cardiovascular disease and decreased immune function) health ramifications [34].

The percentage probable cases (scores $\geq 11$ ) reported here for anxiety (males: $28.8 \%$; females: $42.8 \%$ ) and depression (males: $12.5 \%$; females: $18.9 \%$ ) were notably higher than reported general population norms for anxiety (males: 12.5\%; females: $19.0 \%$ ) and depression (males: $6.9 \%$; females: $6.9 \%$ ) in the UK [35]. Compared to farming populations, the anxiety and depression caseness percentages here are notably higher than reported for farmers in France [19]. The overall, male, and female HADS scores and possible caseness percentages are considerably higher than those reported for farmers in two studies in Norway [6, 8], and in the UK [2]. The HADS scores and percentage of participants 
Table 2 Hospital Anxiety and Depression Scale (HADS) subscale and total scores, and the prevalence of anxiety, depression, and psychological distress caseness amongst farmers in Canada (September 2015-February 2016)

\begin{tabular}{|c|c|c|c|c|c|c|c|c|}
\hline & $N$ & Mean (SD) & Median (IQR) & Normal (0-7) \# (\%) & Mild (8-10) \# (\%) & $\begin{array}{l}\text { Moderate } \\
(11-14) \# \\
(\%)\end{array}$ & Severe $(15-21) \#(\%)$ & $\begin{array}{l}\text { Probable Case } \\
(11-21) \#(\%)\end{array}$ \\
\hline \multicolumn{9}{|c|}{ Anxiety subscale (HADS-A) } \\
\hline Total & 1038 & $8.6(4.5)$ & $8(5-12)$ & $450(43.4)$ & $243(23.4)$ & $235(22.6)$ & $110(10.6)$ & $345(33.2)$ \\
\hline Male & 677 & $8.1(4.4)$ & $8(5-11)$ & $320(47.3)$ & $162(23.9)$ & $140(20.7)$ & $55(8.1)$ & $195(28.8)$ \\
\hline Female & 297 & $9.6(4.5)$ & $10(6-12)$ & $105(35.3)$ & $65(21.9)$ & $83(28.0)$ & $44(14.8)$ & $127(42.8)$ \\
\hline $\begin{array}{l}\text { Gender } \\
\text { miss- } \\
\text { ing or } \\
\text { gender- } \\
\text { queer }^{\mathrm{a}}\end{array}$ & 64 & $9.5(4.6)$ & $9(6-13)$ & $25(39.0)$ & $16(25.0)$ & $12(18.8)$ & $11(17.2)$ & $23(35.9)$ \\
\hline \multicolumn{9}{|c|}{ Depression subscale (HADS-D) } \\
\hline Total & 1039 & $6.1(4.1)$ & $6(3-9)$ & $685(65.9)$ & $202(19.4)$ & $113(10.9)$ & $39(3.8)$ & $152(14.6)$ \\
\hline Male & 678 & $5.9(4.0)$ & $5(3-8)$ & $460(67.8)$ & $133(19.6)$ & $65(9.6)$ & $20(3.0)$ & $85(12.5)$ \\
\hline Female & 297 & $6.5(4.3)$ & $6(3-9)$ & $187(63.0)$ & $54(18.2)$ & $41(13.8)$ & $15(5.0)$ & $56(18.9)$ \\
\hline $\begin{array}{l}\text { Gender } \\
\text { miss- } \\
\text { ing or } \\
\text { gender- } \\
\text { queer }^{\mathrm{a}}\end{array}$ & 64 & $6.7(4.6)$ & $7(4-9)$ & $38(59.4)$ & $15(23.4)$ & $7(10.9)$ & $4(6.3)$ & $11(17.2)$ \\
\hline \multicolumn{3}{|c|}{ Total score (HADS-total) } & $n$ & \multicolumn{2}{|l|}{ Mean (SD) } & \multicolumn{2}{|l|}{ Median (IQR) } & $\begin{array}{l}\text { Psychological } \\
\text { distress }(\geq 12) \\
\#(\%)\end{array}$ \\
\hline \multicolumn{3}{|l|}{ Total } & 1038 & \multicolumn{2}{|l|}{$14.7(7.8)$} & \multicolumn{2}{|l|}{$14(9-20)$} & $642(61.9)$ \\
\hline \multicolumn{3}{|l|}{ Male } & 677 & \multicolumn{2}{|l|}{$14.0(7.6)$} & \multicolumn{2}{|l|}{$13(8-19)$} & $400(59.1)$ \\
\hline \multicolumn{3}{|l|}{ Female } & 297 & \multicolumn{2}{|l|}{$16.1(8.1)$} & \multicolumn{2}{|l|}{$16(10-22)$} & $201(67.7)$ \\
\hline \multicolumn{3}{|c|}{$\begin{array}{l}\text { Gender missing or gender- } \\
\text { queer }^{\mathrm{a}}\end{array}$} & 64 & \multicolumn{2}{|l|}{$16.1(8.5)$} & \multicolumn{2}{|l|}{$14.5(9.5-22)$} & $41(64.1)$ \\
\hline
\end{tabular}

${ }^{a}$ Includes two participants who identified as gender-queer; their results have not been reported separately for reasons related to anonymity and small group size

classified with anxiety and depression are very similar to those reported for farmers in the UK [32]. Nearly two-thirds of participants were classified as having experienced psychological distress (HADS-total $\geq 12$ ). We were able to find only one other study that reported HADS-total in farmers for comparison; our HADS-total score results were higher than those reported by Eisner et al. for a group of farmers after the 1996 'beef crisis' in the UK [36]. The impact of anxiety, depression, and psychological distress on farm productivity is not well investigated; however, anxiety and depression have been reported to increase both absenteeism and presenteeism (i.e., working while ill), and presenteeism has been reported to be associated with work impairment and productivity loss [37]. Hence, in addition to important personal ramifications, poor mental health could have productivity implications for farmers as well.

Resilience is a "dynamic process wherein individuals display positive adaptation despite experiences of significant adversity or trauma" and is not "a personality trait or an attribute of the individual" [38; p. 858]. The average resilience scores of farmers in the present study (71.1) were lower than population norms reported for several general populations in the US (range 75.7-83.0) [39]. This is especially concerning given that resilience helps guard against the negative impacts of stress, and protects against negative mental health outcomes [13]. Many of the stresses that farmers face would be difficult, if not impossible, to eliminate (e.g., weather and disease outbreaks). Yet, resilience is a process that can be learned, and, thus, could help to protect farmers from negative stress and better thrive in their demanding occupations [40]. Greenhill and colleagues identified eight themes that influenced farmer resilience; several of which are reasonably actionable and could be used to promote farmer wellness. For example, being "more than a farmer" (e.g., hobbies and sport, and valuing other social roles like community leaders, parents), having "opportunities to disengage" (e.g., getting off-farm, and time with children, family, friends, community), and self-care (exercise, 
time to self, and time with friends) [40; p. 322]. Indeed, social support and sense of community have been reported to be positively correlated with male farmer well-being [31, 41]. Strategies to provide resilience training to farmers, and help them identify realistic, practical wellness activities could help farmers to better cope with the multitude of occupational stresses which they face.

Compared to males, female participants scored less favorably on all of the mental health outcomes studied here. This supports Booth and Lloyd [2] where female farmers in the UK reported higher scores for stress, depression, and anxiety than their male counterparts, and Brumby et al. [42] where female farmers in Australia scored higher in psychological distress than male farmers, as well as gender differences in mental health outcomes in the general population [43]. Females are reported to face numerous unique challenges in farming that can negatively impact their wellness $[4,40]$. Two individuals identified as gender-queer, which regrettably, is too small a sample for analysis. This may serve as a reminder of the importance of gender diversity in questionnaires (indeed, both individuals thanked us for using an open-ended question for gender) and may inform lines of future research inquiry. Although this study was not designed to explore reasons for gender differences in farmer mental health, our results suggest that such investigation would be useful. Females and gender-queer individuals may represent a priority area for future research and interventions.

In addition to the implications of poor mental health on individual well-being and on farm productivity discussed above, another important consideration is the potential impact on animal welfare. The interdependence of farmer well-being and animal welfare has been described [44], and animal neglect cases have been reported to be associated with mental health and addiction issues, in addition to social problems, amongst the farmers that care for them $[45,46]$. This concept of one welfare, which "recognizes the interconnections between animal welfare, human well-being, and the environment" [47; p. 412], represents an important area for further study.

\section{Limitations}

This cross-sectional study investigated mental health outcomes at one point in time, and did not use random sampling; thus, it represents only a 'snap-shot' of the mental health of participating Canadian farmers and limits the ability to infer causation. A French version of the survey was not offered, which limited our ability to reach French speaking members of our agricultural community; this oversight will be corrected in future work. The resulting limitations on generalizability of the study findings should be considered.
The sample of 1132 farmers represents approximately $0.6 \%$ of all farm operators in Canada [29]. While we did not have data on non-responders, there were no significant $(p \leq 0.05)$ associations between the mental health indices and time of survey completion (data not shown), with one exception: late responders were less likely to be classified in the severe anxiety category of HADS than people who responded early and mid-way through the data collection period $\left(\chi^{2}=28.2 ; p=0.021\right)$. As such, severe anxiety may be over-represented in our sample. However, it has been reported that people experiencing poor mental health are less likely to participate in surveys, which would underestimate the prevalence of mental illness [48]. As a broad approach to sampling was used (i.e., participants were not recruited proportionally by commodity type or by province), our sample is not proportional to the commodity structure or provincial breakdown in Canada (Table 1). The use of formal sampling frames (e.g., membership lists of agricultural organizations) and random sampling procedures proportional to commodity structure would help to avoid issues with sampling bias in future studies.

Our networking with farmers and the agricultural industry during survey development underscored the importance of having a succinct survey for this population. As such, several variables of interest (e.g., alcohol and drug use, suicide ideation, and suicide) were dropped from the questionnaire. Still, we observed a tendency for participants to stop answering questions near the end of the survey (e.g., approximately 1100 responses at the beginning of the survey vs. 965 toward the end). This highlights a methodological challenge of survey research and affirms that questionnaire length, completion time, and response effort are important considerations in designing assessment tools for this population. The use of quantitative research methods also limits the depth of exploration; qualitative approaches would complement these findings and enhance our understanding of farmer mental health.

\section{Public health implications}

The results on perceived stress, anxiety, depression, and low resilience amongst Canadian farmers underscore concerns and illustrate a critical need for research and interventions related to farmer mental health. Indeed, farmer mental health has recently been identified as a priority by Canada's House of Commons agricultural committee [49]. In addition, a bipartisan bill, The Stemming the Tide of Rural Economic Stress and Suicide (STRESS) Act, recently introduced to the US government, calls for increased mental health services for farmers and ranchers [50]. The findings reported here can help to guide policy makers, physicians, and public and mental health service providers in terms of decision-making, 
policy recommendations, resource allocation, and mental health service and training provision.

Acknowledgements We are indebted to the farmers who participated this survey, as well as the numerous agricultural and veterinary organizations who promoted the survey to their membership. The primary author's University of Guelph general research funds were used to conduct this research.

\section{Compliance with ethical standards}

Conflict of interest On behalf of all authors, the corresponding author states that there is no conflict of interest.

Ethical standards All participants provided informed written consent prior to starting the questionnaire, and the data were collected anonymously. The Research Ethics Board at the University of Guelph approved the study (15-JN-007).

Open Access This article is distributed under the terms of the Creative Commons Attribution 4.0 International License (http://creativeco mmons.org/licenses/by/4.0/), which permits unrestricted use, distribution, and reproduction in any medium, provided you give appropriate credit to the original author(s) and the source, provide a link to the Creative Commons license, and indicate if changes were made.

\section{References}

1. Lowe JM, Griffith GR, Alston CL (1996) Australian farm work injuries: incidence, diversity and personal risk factors. Aust J Rural Health 4:178-189. https://doi.org/10.1111/j.1440-1584.1996. tb00207.x

2. Booth NJ, Lloyd K (2000) Stress in farmers. Int J Soc Psychiatry 46:67-73. https://doi.org/10.1177/002076400004600108

3. Walker JL, Walker JS (1988) Self-reported stress symptoms in farmers. J Clin Psychol 44:11-16

4. Fraser CE, Smith KB, Judd F et al (2005) Farming and mental health problems and mental illness. Int J Soc Psychiatry 51:340 349. https://doi.org/10.1177/0020764005060844

5. Kallioniemi MK, Simola A, Kaseva J, Kymäläinen HR (2016) Stress and burnout among Finnish dairy farmers. J Agromed 21:259-268. https://doi.org/10.1080/1059924X.2016.1178611

6. Sanne B, Mykletun A, Moen BE et al (2004) Farmers are at risk for anxiety and depression: the Hordaland Health Study. Occup Med (Chic Ill) 54:92-100. https://doi.org/10.1093/occmed/kqh00 7

7. Elliott M, Heaney CA, Wilkins JR III et al (1995) Depression and perceived stress among cash grain farmers in Ohio. J Agric Saf Health 1:177-184

8. Torske MO, Hilt B, Glasscock D et al (2016) Anxiety and depression symptoms among farmers: the HUNT Study, Norway. J Agromed 21:24-33. https://doi.org/10.1080/10599 24X.2015.1106375

9. Brumby S, Chandrasekara A, McCoombe S et al (2012) Cardiovascular risk factors and psychological distress in Australian farming communities. Aust J Rural Health 20:131-137. https://doi.org /10.1111/j.1440-1584.2012.01273.x

10. Hounsome B, Edwards RT, Hounsome N, Edwards-Jones G (2012) Psychological morbidity of farmers and non-farming population: results from a UK survey. Community Ment Health J 48:503-510. https://doi.org/10.1007/s10597-011-9415-8

11. Government of Canada (2017) An overview of the Canadian agriculture and agri-food system. http://www.agr.gc.ca/eng/about-us/ publications/economic-publications/an-overview-of-the-canad ian-agriculture-and-agri-food-system-2017/?id=1510326669269. Accessed 23 Nov 2018

12. Food and Agriculture Organization of the United Nations (FAO). How to feed the World in 2050. http://www.fao.org/fileadmin/ templates/wsfs/docs/expert_paper/How_to_Feed_the_World _in_2050.pdf. Accessed 23 Nov 2018

13. Connor KM, Davidson JRT (2003) Development of a new resilience scale: the Connor-Davidson Resilience Scale (CD-RISC). Depress Anxiety 18:76-82. https://doi.org/10.1002/da.10113

14. Lee E-H (2012) Review of the psychometric evidence of the perceived stress scale. Asian Nurs Res (Korean Soc Nurs Sci) 6:121-127. https://doi.org/10.1016/j.anr.2012.08.004

15. Cohen S, Kamarck T, Mermelstein R (1983) A global measure of perceived stress. J Health Soc Behav 24:385-396

16. Snaith RP, Zigmond AS (1994) The Hospital Anxiety and Depression Scale with the Irritability-Depression-Anxiety Scale and the Leeds Situational Anxiety Scale manual. GL Assessment, London

17. Bartram DJ, Yadegarfar G, Baldwin DS (2009) A cross-sectional study of mental health and well-being and their associations in the UK veterinary profession. Soc Psychiatry Psychiatr Epidemiol 44:1075-1085. https://doi.org/10.1007/s00127-009-0030-8

18. Bjelland I, Dahl AA, Haug T, Neckelmann D (2002) The validity of the Hospital Anxiety and Depression Scale an updated literature review. J Psychosom Res 52:69-77

19. Guillien A, Laurent L, Soumagne T et al (2018) Anxiety and depression among dairy farmers: the impact of COPD. Int J COPD 12:1-9. https://doi.org/10.2147/COPD.S143883

20. Cosco TD, Doyle F, Ward M, McGee H (2012) Latent structure of the Hospital Anxiety and Depression Scale: a 10-year systematic review. J Psychosom Res 72:180-184. https://doi.org/10.1016/j. jpsychores.2011.06.008

21. Pallan JF, Tennant A (2007) An introduction to the Rasch measurement model: an example using the Hospital Anxiety and Depression Scale (HADS). Br J Clin Psychol 46:1-18. https:// doi.org/10.1348/014466506X96931

22. Ahern NR, Kiehl EM, Lou Sole M, Byers J (2006) A review of instruments measuring resilience. Issues Compr Pediatr Nurs 29:103-125. https://doi.org/10.1080/01460860600677643

23. Dohoo I, Martin W, Stryhn H (2012) Sampling. Methods in epidemiologic research. VER Inc., Charlottetown, pp 48-50

24. van der Heijden GJMG, Donders TAR, Stijnen T, Moons KGM (2006) Imputation of missing values is superior to complete case analysis and the missing-indicator method in multivariable diagnostic research: a clinical example. J Clin Epidemiol 59:11021109. https://doi.org/10.1016/j.jclinepi.2006.01.015

25. Lindner JR, Murphy TH, Briers GE (2010) Handling nonresponse in social science research. J Agric Educ 42:43-53. https://doi. org/10.5032/jae.2001.04043

26. Statistics Canada Table 32-10-0442-01 Statistics Canada 2016 Census of Agriculture-Farm operators classified by number of operators per farm and age. https://www150.statcan.gc.ca/t1/tbl1/ en/tv.action?pid=3210044201. Accessed 21 May 2019

27. Statistics Canada Table 32-10-0441-01 Statistics Canada 2016 Census of Agriculture-Farm operators classified by number of operators per farm and sex. https://www150.statc an.gc.ca/t1/tbl1/en/tv.action?pid=3210044101\&pickMember $\mathrm{s} \% 5 \mathrm{~B} 0 \% 5 \mathrm{D}=1.1 \&$ pickMembers $\% 5 \mathrm{~B} 1 \% 5 \mathrm{D}=3.3$. Accessed 21 May 2019

28. Statistics Canada Table 32-10-0440-01 Statistics Canada 2016 Census of Agriculture-Total number of farms and farm operators, by province. https://www150.statcan.gc.ca/t1/tbl1/en/tv.actio 
n?pid=3210044001\&pickMembers\%5B0\%5D=1.2179. Accessed 21 May 2019

29. Statistics Canada Table 32-10-0403-01 Statistics Canada 2016 Census of Agriculture-Farms classified by farm type. https:// www150. statcan.gc.ca/t1/tbl1/en/tv.action?pid=3210040301. Accessed 21 May 2019

30. Cohen S, Williamson GM (1988) Perceived stress in a probability sample of the United States. In: Spacapan S, Oskamp S (eds) The social psychology of health. Sage, Newbury Park, pp 31-67

31. Kutek SM, Turnbull D, Fairweather-Schmidt AK (2011) Rural men's subjective well-being and the role of social support and sense of community: evidence for the potential benefit of enhancing informal networks. Aust J Rural Health. https://doi.org/10.11 $11 / \mathrm{j} .1440-1584.2010 .01172 . x$

32. Gregoire A (2002) The mental health of farmers. Occup Med (Chic Ill) 52:471-476

33. Simpson K, Sebastian R, Arbuckle TE et al (2004) Stress on the farm and its association with injury. J Agric Saf Health 10:151-154

34. Schneiderman N, Ironson G, Siegel SD (2005) Stress and health: psychological, behavioral, and biological determinants. Annu Rev Clin Psychol 1:607-628. https://doi.org/10.1146/annurev.clinp sy.1.102803.144141

35. Breeman S, Cotton S, Fielding S, Jones GT (2015) Normative data for the Hospital Anxiety and Depression Scale. Qual Life Res 24:391-398. https://doi.org/10.1007/s11136-014-0763-Z

36. Eisner CS, Neal RD, Scaife B (1999) The effect of the 1996 "beef crisis" on depression and anxiety in farmers and non-farming controls. Br J Gen Pract 49:385-386

37. Johns G (2010) Presenteeism in the workplace: a review and research agenda. J Organ Behav 31:519-542. https://doi. org/10.1002/job.630

38. Luthar SA, Cicchetti D (2000) The construct of resilience: implications for interventions and social policies. Dev Psychopathol $12: 857-885$

39. Davidson J (2018) Connor-Davidson Resilience Scale (CD-RISC) (C) Manual. http://cd-risc.com/CD-RISC Manual 08-19-18.pdf

40. Greenhill J, King D, Lane A, MacDougall C (2009) Understanding resilience in South Australian farm families. Rural Soc 19:318325. https://doi.org/10.5172/rsj.351.19.4.318
41. McLaren S, Challis C (2009) Resilience among men farmers: the protective roles of social support and sense of belonging in the depression-suicidal ideation relation. Death Stud 33:262-276. https://doi.org/10.1080/07481180802671985

42. Brumby S, Kennedy A, Chandrasekara A (2013) Alcohol consumption, obesity, and psychological distress in farming communities - an Australian study. J Rural Health 29:311-319. https ://doi.org/10.1111/jrh.12001

43. World Health Organization (2002) Gender and women's mental health. https://www.who.int/mental_health/prevention/gende rwomen/en/. Accessed 3 Dec 2018

44. Kauppinen T, Vainio A, Valros A et al (2010) Improving animal welfare: qualitative and quantitative methodology in the study of farmers' attitudes. Anim Welf 19:523-536. https://doi. org/10.1177/0309364612448807

45. Devitt C, Kelly P, Blake M et al (2015) An investigation into the human element of on-farm animal welfare incidents in Ireland. Sociol Ruralis 55:400-416. https://doi.org/10.1111/soru.12069

46. Andrade SB, Anneberg I (2014) Farmers under pressure. Analysis of the social conditions of cases of animal neglect. J Agric Environ Ethics 27:103-126. https://doi.org/10.1007/s 1080 6-013-9456-9

47. García Pinillos R, Appleby MC, Manteca X et al (2016) One welfare-a platform for improving human and animal welfare. Vet Rec 179:412-413. https://doi.org/10.1136/vr.i5470

48. Torvik FA, Rognmo K, Tambs K (2012) Alcohol use and mental distress as predictors of non-response in a general population health survey: the HUNT study. Soc Psychiatry Psychiatr Epidemiol 47:805-816. https://doi.org/10.1007/s00127-011-0387-3

49. Parliament of Canada House of Commons Standing Committee on Agriculture and Agri-Food (2019) Mental health: a priority for our farmers. Ottawa, ON

50. Emmer T (2018) 15TH congress 2nd session; stemming the tide of rural economic stress and suicide act. United States of America Congress 